\title{
A Mycological Study of Superficial Mycoses at the Skin Clinic in Sabah, Malaysia.
}

\author{
${ }^{1}$ Mustafa Murtaza, ${ }^{2}$ Sandhya Rajainthran, ${ }^{2}$ Bernadite George \\ ${ }^{1}$ School of Medicine, University Malaysia, Sabah, Kota Kinabalu,Sabah,Malaysia. \\ ${ }^{2}$ Queen Elizabeth Hospital, Kota Kinabalu,Sabah, Malaysia.
}

\begin{abstract}
Superficial fungal infections are common in Sabah. The skin clinic is a tertiary referral center for dermatological diseases in Sabah, and sees more than 7,000 cases of various skin complaints annually. The study analyses data collated from the skin clinic's medical records as well as fungus culture results from the microbiology diagnostic unit. A total of 7325 subjects were screened for superficial mycoses. Of the 7,325 subjects sampled randomly, $180(2.5 \%)$ had lesions suggestive of superficial mycoses. In a total of 190 samples collected, [58.42\%] yielded significant growth by culture. The distribution of superficial mycoses is dependent on age,sex and ethnicity. The most common isolate was Tinea corporis [30,63\%], followed by Tinea cruris [23.62\%], Tinea pedis [16.21\%], T.unguium [20.72\%], in onychomycoses, and T.capitis [6.30\%] and others. A predominance of dermatomatophytoses in the 50 years and above age group was observed. In Sabah State the relative humidity fluctuates between $60 \%$ and $70 \%$ for most part of the year and the area receives heavy rain falls. Thus, the environmental conditions are conducive for development of superficial mycoses.
\end{abstract}

Keywords: Superficial mycoses, Dermatophytoses, Tinea corporis, Tinea cruris,Aspergillus niger

\section{INTRODUCTION}

Dermatophytosis is the superficial mycosis (ringworm) is caused by Dermatophytes. The dermatophytes are the molds that invade the stratum corneum of the skin or other keratinized tissue derived from the epidermis such as hair and nails. They cause infections, dermatophytoses of most skin sites, although the feet, groin, scalp, and nails are most commonly affected[1 ]. The dermatophytes are the earliest microorganisms that were found to cause infections in the humans. Greek Physicians knew about ringworm infections in humans [2]. The factors affecting the distribution and transmission of dermatophytoses are largely dependent on the source of infection-zoophilic, geophilic and anthrophilic [3]. The inflammatory response to dermatophytes varies.In zoophilic and geophilic dermatophytes elicit a brisk inflammatory response in skin and hair follicles. The anthrophilic dermatophytes grow only on human skin, hair or nails. The inflammatory response to anthrophilic fungi is usually mild [4]. The incidence of dermatophytoses is a dynamic situation. The pattern of geographical distribution and prevalence are not fixed. They change continually due to influences of climate, human social and antisocial activities, cultural activities, cultural habits, migration and developments in diagnosis and therapy [5-7]. Many studies on superficial mycoses in different parts of the world have confirmed that host susceptibility may be enhanced by moisture, warmth, specific skin chemistry, composition of sebum and perspiration, age, heavy exposure and genetic predisposition [8-12]. Dermatophytoses is highly contagious and represent a significant public health problem, particularly among school children [13]. Sabah has a warm, moist environment, poor socioeconomic conditions in certain areas, rural population in constant contact with soil and animals and urban population also have pets. The aim of study was to know the prevalence of dermatophytoses among the local population due to favorable environmental conditions for the development of superficial mycosis.

Study Site

\section{METHODS}

Hospital Queen Elizabeth, Kota Kinabalu, Sabah, is a 1000 beds teaching and referral hospital, provides medical health services to a population of 500,000 people around Kota Kinabalu and other districts in Sabah.

Study Protocol

A team of researchers comprising an Assoc. Professor, hospital dermatologist, medical officers, nurses, and laboratory staff were involved in the study. All patients with clinical symptoms of skin mycoses were examined by the dermatologist. Patients with scalp infection screened by using filtered ultraviolet (UV) light of a Wood's lamp; the demonstration of fungal elements inside, surrounding, and penetrating the hair shaft. Patient's blood, urine samples taken for biochemical, hematological and urinalysis assessment. All patients' 
information pertaining to their bio data, clinical features and antibiotic therapy documented in the study protocol.

Study Design

A retrospective review of data from the patient's case notes record as well as fungal culture results from the microbiology diagnostic unit (MDU) from January 2007to $31^{\text {st }}$ December 2009.

Microscopic examination

Superficial skin lesions scraping placed on glass slides and examined unstained in $10 \%$ potassium hydroxide for the presence of hyphae, micro conidia or macro conidia. Hair examined as skin scraping from the superficial skin lesions. Nail scraping examined in the same way but, more time required for clearing of preparation by potassium hydroxide.

\section{Culture method}

All materials from suspected cases of mycosis infections cultured for fungi regardless of whether or not fungus hyphae or spores (fungus cells) detected on direct examination. The skin scraping, hair, and nail scraping cultured on selected media, Mycosel agar slants containing $0.40 \mathrm{mg} / \mathrm{L}$ cyclohexamide, and chloramphenicol $0.05 \mathrm{mg} / \mathrm{L}$ (Becton Dickinson, Maryland), and Sabourauds's Dextrose agar (Merk, VM 182338) containing 20 units of penicillin and 40 units of streptomycin was used for primary isolation of the fungi. The cultures were incubated at room temperature for 1-3 weeks and regularly examined for growth. Rapid urease test, antigen protein-based assays and nucleic acid amplification assays for the detection or identification of dermatophyes was not used in this study.

\section{Identification of isolates}

The cultural characteristics of the isolates, including: the color, texture, and reverse appearance of the colonies were noted. The microscopic characteristics of the hyphae were noted. The fungus isolates were identified by the identification scheme described by Koneman E, Roberts GD (1985).

Data was analyzed using Statistical Package of Social Sciences(SPSS16).The difference between values was considered significant when $\mathrm{P}<0.05$ was obtained.

\section{RESULTS}

Over one year period January to December 2009, there were a total of 7,325 cases of dermatological diseases at the skin clinic. Figure1 shows the annual trends of dermatological cases. Out of 180 patients (98 males and 82 females) who were subjected to mycological studies. Nearly one half $(45.5 \%)$ of patients belonged to the age group of above age 50 years. The difference between the age-sex distribution of males and females is given in the (Table 1).111 (58.42\%) were culture positive while; $80(42.10 \%)$ were $\mathrm{KOH}$ positive.Tinea corporis $(30.63 \%)$ ),followed by Tinea cruris $(23.62 \%)$ and Tinea enguuim -onychomycoses $(20.72 \%)$ were the predominant clinical presentations. Trichophyton rubrum was isolated from $(47.74 \%)$ of the patients (Table 2). Male to female ration was 1.2:

Table 1. Demographic of study population: 180 patients analyzed.

\begin{tabular}{|l|l|}
\hline Variables & No. percentage \\
\hline \multicolumn{2}{|l|}{} \\
\hline \multicolumn{1}{|l|}{} \\
\hline 11 ge group & $17(9.4)$ \\
\hline $21-30$ & $12(6.6)$ \\
\hline $31-40$ & $19(10.5)$ \\
\hline $41-50$ & $24(13.3)$ \\
\hline$>50$ & $26(14.4)$ \\
\hline Gender & $\mathbf{8 2}(45.5)$ \\
\hline Male & $\mathbf{9 8}(54.44)$ \\
\hline Female & $\mathbf{8 2}(45.55)$ \\
\hline Ethnicity & \multicolumn{2}{|l|}{} \\
\hline Kadazan /Dusun/ & $61(33.9)$ \\
\hline Murut & $60(33.3)$ \\
\hline Chinese & $16(9.0)$ \\
\hline Malay & $14(7.8)$ \\
\hline Bajau & $\mathbf{0 3}(1.7)$ \\
\hline Indian & $\mathbf{0 2}(1.1)$ \\
\hline Filipino & $24(13.3)$ \\
\hline Others &
\end{tabular}


A Mycological Study of Superficial Mycoses at the Skin Clinic in Sabah, Malaysia.

Based on hospital record

\begin{tabular}{|l|l|}
\hline Total & $180(100.0)$ \\
\hline
\end{tabular}

2007-2009.

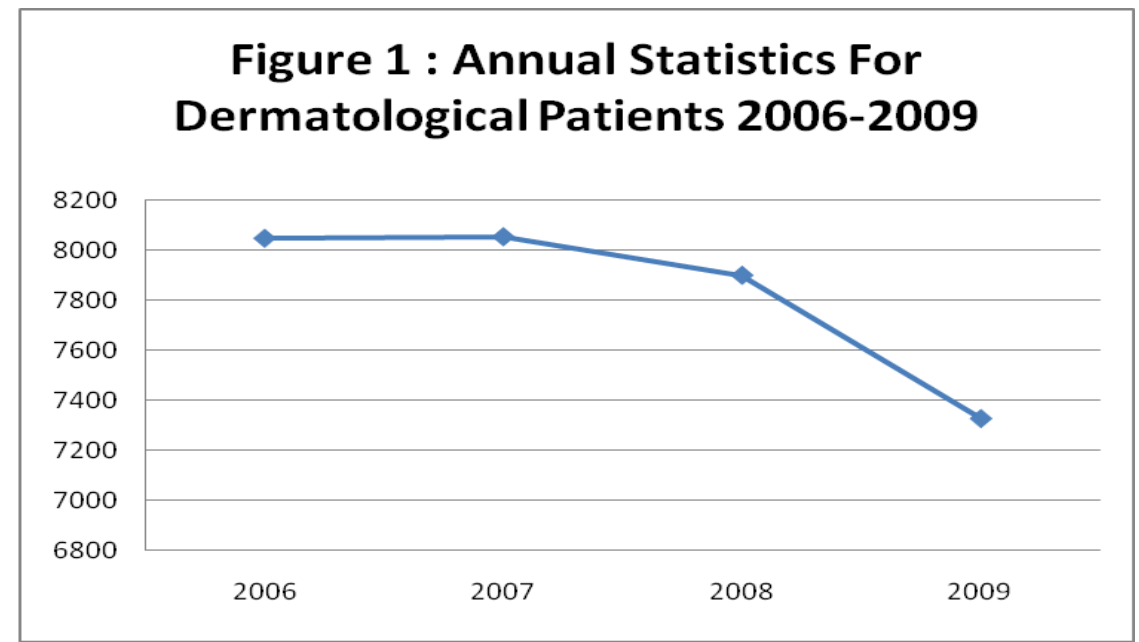

Figure 1. Annual statistic of Dermatological Patients 2007-2009

Table 2: Clinical presentations

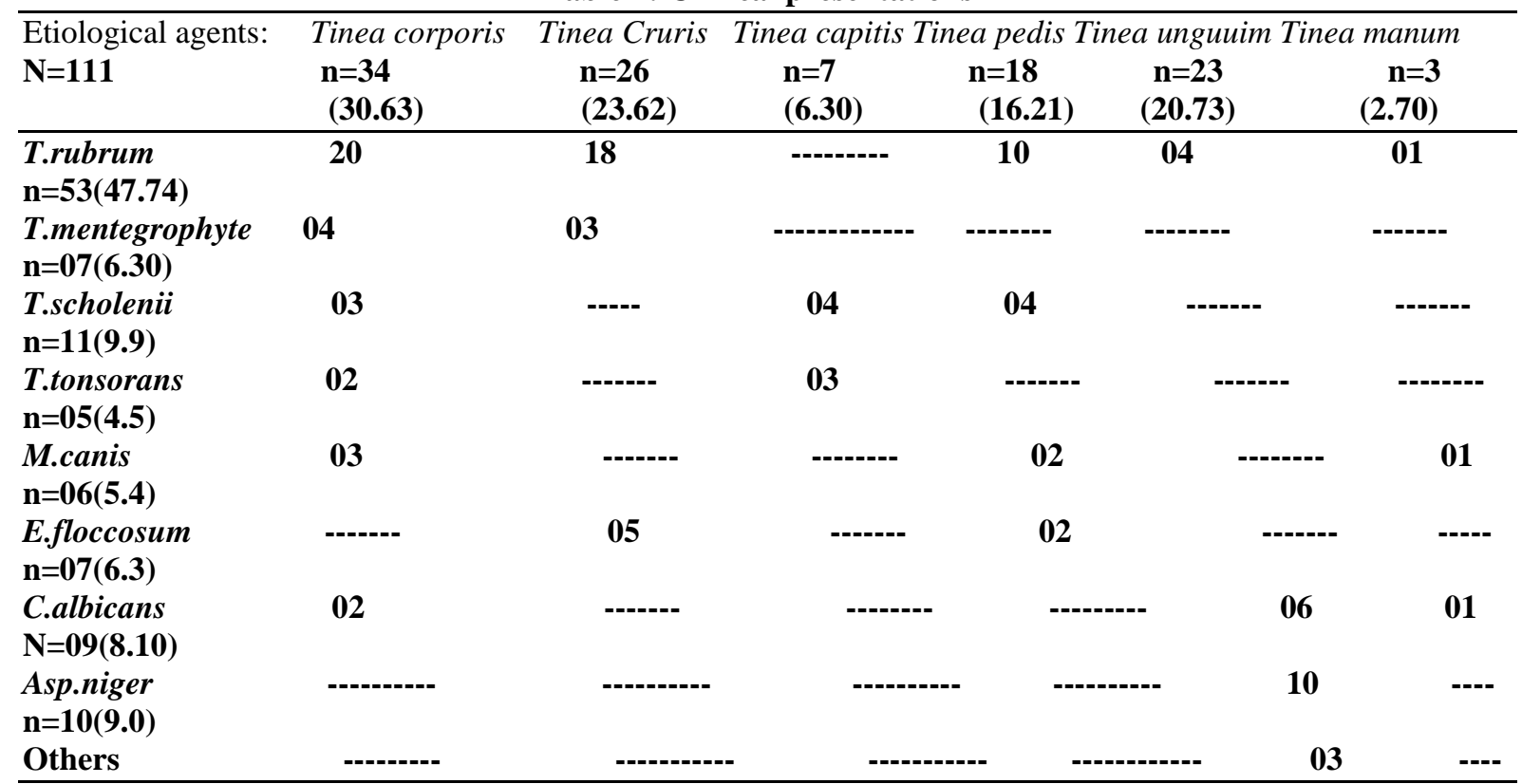

Figures in the parentheses indicate percentage.

IV. DISCUSSION 
In this study the most patients $(45.5 \%)$ were in the 50 years and above age group, vulnerable to fungal infections. In other studies the age group 21-30 years is predominantly affected [15, 16]. The male to female ratio was $1.2: 1$ which is consistent to other researchers ${ }^{16}$. Our $\mathrm{KOH}$ positivity $(42.10 \%)$ lower than other researchers , 58.83\%[16,17].Tinea corporis was the most frequent clinical presentation(30.63\%) while Tinea manum was the least frequent $(2.70 \%)$. This study showed that glabrous skin infection T.corporis was more frequent than scalp infection as reported by other studies [18]. Trichophytomn rubrum was the most common isolate (47.74\%) in our study (Table 2).This is similar to the United Kingdom and Europe, and United States [19-21], the frequency of T.rubrum isolates in other studies were $28.12 \%, 59.76 \%$ and $85.15 \%$ [14-16]. Aspergillus niger and Candida Sps was most frequent isolates in T.unguium-onychomychoses in this study $9.0 \%$, and $8.1 \%$ respectively. This was lower than other studies, $34.82 \%$ and $50.1 \%$ [22, 23]. Other studies isolates were T.mentegrophytes and T.soudanese, and Candida sps[23]. Other researchers also described a feature of relapse of treated nails, but rapidly spreading proximal nail plate invasion in patients with AIDS [25]. This study has its limitations: There was no information on the prevalence of common fungal pathogens isolated during the last two decade. In one study in the $80 \mathrm{~s}$ the most prevalent fungal pathogen was T.mentegrophytes,followed by T.rubrum and Epidermatophyton floccosum [26], but a recent study reported T.corporis, and T.rubrum was responsible for $75.2 \%$ of the isolates [22]. Study also lacks information on the level of education of the families of school Children. Superficial mycoses are more prevalent in the children came from families with low level of education [13]. Further study is needed to know more on superficial mycoses and to address some of the questions raised in this study.

\section{CONCLUSION}

The study at Skin clinic from January 2007 to December 2009 reveals the incidence of Mycoses in 180 patients with peak occurring in patient aged 50 years and above. Lesions suggestive of superficial mycoses was more common in males than in females and in ethnic Kadazan's and ethnic Chinese .Tinea corporis, Tinea cruris were most common isolate followed by T.unguium and T.capitis. The environmental conditions are conducive for development of superficial mycoses.

\section{ACKNOWLEDGEMENTS}

The authors wish to thank Vice Chancellor, University Malaysia, Sabah, Director General Ministry of Health Malaysia, Director Health Services Sabah, and Dean School of Medicine for permission to publish this paper. Thanks also to the technical support of MDU staff. Financial support of UMS is gratefully acknowledged. Ministry of Health Malaysia, NMRR (IDN0:09-447-4153).

\section{REFERENCES}

[1]. Rebell G,Taplin D. Dermatophytes. Their recognition and identification. $2^{\text {nd }}$ ed.Miami:University Press. 1970.

[2]. De Vroey C. Epidemiology of ringworm (dermatophytosis).Semin Dermitol.4:185-200.1985.

[3]. Rippon JW.Epidemiology and emerging patterns of dermatophyte species.In current Topics in Medical Mycology 1.New York: Springer-Verlag; 208-34.1985.

[4]. Borman AM,Cambel CK,Fraser M,Johnson EM:Analysis of the dermatophyte species isolated in the British Isles between 1980and 2005 and review of Worldwide dermatophyte trends over the last three decades.Med.Mycol 2007;45-131.

[5]. George L.Epidemiology of Dermatophytes.Source of infection.mode of transmission and endemicity.Ann $N$ Y Acad 89,1960

[6]. English MP, Gibson MD. Studies in the epidemiology of tinea pedis. Tinea pedis in school children.11.Dermatophytes on the floor of swimming baths. Br Med,J 1442-1448.1972.

[7]. $\quad$ English MP.The epidemiology of animal ringworm in Man.Br Dermatol 86 (suppl 8) 78.1972.

[8]. Ellabib MG, Khalifa ZM.Dermatophyte and other fungi associated with skin mycoses in Tripoli Libya.Ann.Saudi Med.21:34.2001.

[9]. Staats CC,Korstanje MJ.Fungal infections in the Netherlands:Prevailing fungi and pattern of infection.Dermatol.190:39-42.1995.

[10]. Ayadi A,Borgi N,Makni F.Prevalence of superficial mycoses in urban ecosystem in Sfax (Tunisia)Bull.Soc.Pathol.Exotique.86:188-9.1993.

[11]. Venugopal PV,Venugopal TV.Tinea capitis in Saudi Arabia.Int.J.Dermatol.32:39-40

[12]. Brooks GF,Butel JS,Morse MA.Jawets Melnick and Adelberge's Medical Microbiology.23 ${ }^{\text {rd }}$

[13]. ed.McGraw- Hill Education Press,Asia.pp 629-632.2004.

[14]. Fathi HI, AI-Samarai AGM. Prevalence of Tinea among school children in Iraq.East Medit.Health J. 6:128-137.

[15]. Koneman E,Roberts G:Practical laboratory mycology, ed 3,Baltimore, 1985,William \& Wilkins.

[16]. Patwardhan N,Dave T.Dermatophytosis in and around Aurangabad.Ind.J.Path.and Microbiol.1999;42(4)455-62.

[17]. Chowdhary A,Deshmukh AB,Bansal MP,Deshpande AD.Study of dermatophytoses at Aurangabad.Ind.J.Med.Microbiol. 1986; 32:229-32.

[18]. Huda NN,Charkraborty N,Sharma JN,Bordolol.A Clinico-mycological study of superficial mycoses in upper assam.Ind.J.Dermatol,Venereology and Leprology 1995;61:329-32.

[19]. Enemuor SC,Amedu AS.Prevalence of superficial mycoses in primary school children in Anyigba,Kogi State,Nigeria.African J.Microbiol Resch.vol.3(2) pp.062-065.2009.

[20]. Hay RJ:Superficial mycoses In Fungi and Skin Disease,chapter four,pp.13-27,Mosby-Wolf,London,1993.

[21]. Hay RJ:The Achilles Project:How common are fungal foot in Europe?Satellite symposium.English Congress of European Academy of Dermatology and Venereology (EADV), 1999.

[22]. Aly R: Ecology and epidemiology of dermatophyte infections.J Am Acad Dermatol 31(3)pt2):S21-25,1994. 
[23]. Hiok Hee Tan.Superficial Fungal Infections seen at the National skin Centre,Singapore.Jpn.J.Med.Mycol.Vol.4677-80,2005.

[24]. Kusmarinah Bramono,Unandar Budimulja.Epidemiology of Onychomycoses in Indonesia:Data Obtained from Three Individual Studies.Jpn.J.Med.Mycol.46,171-176,2005.

[25]. Kalter DC,Hay RJ.Onychomycoses due to Trichophyton soudanense.Clin Exp Dermatol.1988;13:24-7.

[26]. WeismannK,Knudsen EA,Pedersen C.Wite nails in AIDS/ARC due to Trichophyton rubrum Infection.ClinExp Dermatol.1988;13:24-7.

[27]. Giam YC,Rajan VS:Evaluation of ketakonzole against griseofulvin in the treatment of dermatopytes.Singapre Med.J 25:2607,1992 . 